\title{
Improving the environmental sustainability of reusable food containers in Europe
}

DOI:

10.1016/j.scitotenv.2018.02.128

\section{Document Version}

Accepted author manuscript

Link to publication record in Manchester Research Explorer

\section{Citation for published version (APA):}

Gallego Schmid, A., Fernandez Mendoza, J. M., \& Azapagic, A. (2018). Improving the environmental sustainability of reusable food containers in Europe. Science of the Total Environment. https://doi.org/10.1016/j.scitotenv.2018.02.128

\section{Published in:}

Science of the Total Environment

\section{Citing this paper}

Please note that where the full-text provided on Manchester Research Explorer is the Author Accepted Manuscript or Proof version this may differ from the final Published version. If citing, it is advised that you check and use the publisher's definitive version.

\section{General rights}

Copyright and moral rights for the publications made accessible in the Research Explorer are retained by the authors and/or other copyright owners and it is a condition of accessing publications that users recognise and abide by the legal requirements associated with these rights.

\section{Takedown policy}

If you believe that this document breaches copyright please refer to the University of Manchester's Takedown Procedures [http://man.ac.uk/04Y6Bo] or contact uml.scholarlycommunications@manchester.ac.uk providing relevant details, so we can investigate your claim.

\section{OPEN ACCESS}




\title{
Improving the environmental sustainability of reusable food containers in Europe
}

Alejandro Gallego-Schmid*, Joan Manuel F. Mendoza and Adisa Azapagic

Sustainable Industrial Systems, School of Chemical Engineering and Analytical Science, The University of Manchester, The Mill, Sackville Street, Manchester, M13 9PL, UK

(*) Corresponding author: alejandro.gallegoschmid@manchester.ac.uk

\begin{abstract}
Modern lifestyles have popularised the use of food containers, also known as food savers or Tupperware. However, their environmental impacts are currently unknown. To fill this knowledge gap, this paper presents the first comprehensive assessment of the life cycle environmental sustainability of reusable plastic and glass food savers and evaluates different options for improvements, focusing on European conditions. Taking a cradle-to-grave approach, the paper considers twelve environmental impacts, including global warming potential (GWP), acidification, eutrophication, human and ecotoxicities. The results suggest that, for example, the total GWP of using both types of food saver in the European Union (EU) amounts to $653 \mathrm{kt} \mathrm{CO}_{2}$ eq./year, equivalent to the annual greenhouse gas emissions of Bermuda. The use stage is the main contributor to the impacts $(>40 \%)$, related to the washing of containers. Glass food savers have $12 \%-64 \%$ higher impacts than the plastic and should have up to 3.5 times greater lifespan to match the environmental footprint of plastic containers. Three improvement scenarios have been considered at the EU level for the year 2020: low-carbon electricity mix; implementation of the EU eco-design regulation for dishwashers; and adoption of more resource-efficient hand dishwashing techniques. The results suggest that the implementation of all three improvement options would reduce the impacts by $12 \%-47 \%$. The option with the greatest potential for reducing the impacts (12\%$27 \%$ ) is improved hand dishwashing to reduce the amount of water, energy and detergents used. Thus, policy makers and manufacturers should devise strategies to raise awareness and guide consumers in adopting these techniques with the aim of reducing the environmental impacts associated with reusable food savers used by millions of people worldwide.
\end{abstract}

Keywords: life cycle assessment (LCA); eco-design; energy efficiency; global warming; food containers; environmental impacts. 


\author{
Abbreviations \\ $\mathrm{ADP}_{\mathrm{e}}$ : abiotic depletion potential of elements \\ $\mathrm{ADP}_{\mathrm{f}}$ :abiotic depletion potential of fossil resources \\ AP: acidification potential \\ BAT: best available technology \\ DCB: dichlorobenzene \\ EP: eutrophication potential \\ EU: European Union \\ FAETP: freshwater aquatic ecotoxicity potential \\ GWP: global warming potential \\ HTP: human toxicity potential \\ LCA: life cycle assessment \\ MAETP: marine aquatic ecotoxicity potential \\ ODP: ozone depletion potential \\ PE: polyethylene \\ PED: primary energy demand \\ PET: polyethylene terephthalate \\ PLA: polylactic acid \\ POCP: photochemical oxidants creation potential \\ PP: polypropylene \\ PS: polystyrene \\ TETP: terrestrial ecotoxicity potential
}




\section{Introduction}

Reusable food savers, also known as food containers, lunch boxes or Tupperware, are used worldwide and their popularity is growing. This is due to the increasing out-of-home consumption of food as a result of changing work and recreational habits (Razza et al., 2009). Reusable food savers are used for temporary food storage, preserving food quality and safety through mechanical and physico-chemical protection in a practical and costeffective way (Marsh and Bugusu, 2007). One of the main manufacturers of food savers, Tupperware, reported net sales of $\$ 2.35$ billion and an active sales workforce of more than 530,000 in 2013 (Tupperware, 2014). In the European Union (EU) ${ }^{1}, 42 \%$ of meals consumed by employees at work are brought from home (FOOD Programme, 2015). Given that 144.4 million employees work full time in the EU (Teichgraber, 2015), the number of food savers used annually in the EU could be substantial. Therefore, the environmental impacts related to the production, use and disposal of these products could be significant.

However, so far, research on the life cycle environmental sustainability of reusable food savers has been scarce. Only two life cycle assessment (LCA) studies have been found in the literature, both limited in scope. One of these (Harnoto, 2013) considered three environmental burdens - greenhouse gas emissions, energy consumption and waste generation - associated with reusable polypropylene (PP) containers. These were compared with the containers made of compostable bagasse used in the main canteen of the University of Berkley. The study found that the reusable PP containers required 15 uses to equal the burdens of the equivalent number of compostable containers. The second study (Accorsi et al., 2014) considered global warming potential of four food containers used in the catering industry in Italy. The authors concluded that the use of PP reusable containers had a lower impact than the non-reusable alternatives made of cardboard, plastic and wood.

The other LCA studies related to food containers focused on various non-reusable options. For instance, Kuo et al. (2005) considered food boxes used for take-away food in Taiwan, made from paper, PP and polystyrene (PS). They estimated the environmental burdens and costs of pollution control associated with the production of the boxes. The PP box had the highest cost for air pollution control and the paper for waste and water pollution control. Another study (Suwanmanee et al., 2013) compared the environmental performance of three non-reusable thermoform boxes made from polystyrene (PS) and polylactic acid (PLA) produced from corn and cassava starch. This cradle-to-gate study considered three impacts: global warming, acidification and photochemical oxidants formation. The results suggested that the impacts were higher for the PLA than the PS container, especially for global warming, because of the indirect land-use change related to cultivation of corn and cassava. Madival et al. (2009) also considered PLA and PS thermoforms (used for strawberry packaging) and compared them with polyethylene terephthalate (PET) packaging, concluding that the last had the highest impacts.

Plastic food savers have the greatest share of the market owing to their low cost, light weight and functional advantages, such as microwavability, optical properties and availability of various sizes and shapes (Duraccio et al., 2013). However, some organisations have suggested that these types of food saver could have negative effects on health because of the potential leaching into the food of toxic chemicals, such bisphenols A, S and F (NRDC, 2011; Earth Talk, 2008). Scientific studies, on the other hand, claim that these concerns are unfounded (EFSA, 2015; Harvard Health 2015; Marsh and Bugusu, 2007). As a consequence of this debate, glass food savers have emerged as an alternative to plastic containers, particularly for people concerned about health (Girling, 2003). In addition to being chemically inert, they are resistant to staining, easy to recycle and give an impression of a 'higher quality' product. Therefore, this paper focuses on plastic and glass reusable food

\footnotetext{
${ }^{1}$ The term "EU" used throughout the paper refers to the union of 28 member countries (EU28).
} 
savers to evaluate their life cycle environmental sustainability and identify opportunities for improvements by the means of LCA.

As the focus is on reusable food savers, their use could have significant contribution to environmental impacts at the EU level because they need to be cleaned after each use, either manually or in a dishwasher, requiring water, energy and detergents. This is particularly important as dishwashing contributes considerably towards global warming, human toxicity and fossil fuel depletion (Arendorf et al., $2014 \mathrm{a}, \mathrm{b}$ ). Furthermore, dishwashers consume around $1 \%$ of the electricity used annually in the EU (ECEEE, 2013; ENTSO-E, 2011), equivalent to the electricity produced by ten gas power plants (DECC, 2015). To improve the environmental performance of household dishwashers, the European Commission (2010) has developed an eco-design regulation (No. 1016/2010) for these appliances. In the case of hand dishwashing, several studies at the EU level have demonstrated the importance of consumer behaviour for reducing the amount of energy, water and soap used (Stamminger et al., 2007; Fuss and Stamminger, 2010; Fuss et al., 2011) but no specific EU policy has been developed so far to address this issue. Therefore, it is important to consider the effects on the environmental impacts of food savers of both manual and machine dishwashing to identify opportunities for improvements. For this reason, two scenarios related to this are considered in the paper: i) the implementation of the eco-design regulation for dishwashers; and ii) use of best available techniques (BAT) for hand washing up. These are compared with a third scenario related to the expected decarbonisation trend of the electricity mix in the EU. All three scenarios refer to the year 2020 and are evaluated against the present situation for the reusable food savers. To our knowledge, this is the first study of its kind internationally.

\section{Materials and methods}

The study has been carried out according to the ISO 14040/44 methodological guidelines for LCA (ISO, 2006a,b). The goal and scope of the study is described in the next section. This is followed first by the inventory data for the individual plastic and glass food savers and then by the assumptions for the food savers used at the EU level. The impact assessment method used to estimate the impacts is described in section 2.3.

\subsection{Goal and scope of the study}

The main goals of the study are:

i) to evaluate and compare the life cycle environmental sustainability of reusable plastic and glass food savers;

ii) to identify environmental hotspots and evaluate opportunities for improvements at the EU level.

The functional unit of the study is defined as "50 uses of plastic (polypropylene) and glass food savers over their lifetime". The number of uses is based on the data for plastic containers found in the literature (Accorsi et al., 2014). The same lifespan has been considered for the glass food savers due to a lack of specific data. It can be argued that glass containers are more durable than plastic food savers and would last longer. However, they are also more prone to breaking on impact. In the absence of data on the average lifetime of glass containers, the minimum number of times it must be used to equal the impacts of plastic food savers has been calculated for comparison purposes. Acknowledging that the lifespan of both types of food savers is uncertain as it is highly dependent on the use and maintenance conditions, the influence of this parameter on the impacts has been considered in a sensitivity analysis (see section 3.2.2.).

The assumed volume for both types of container is $1.1 \mathrm{~L}$, the best-selling size in the product range considered, according to the manufacturer that provided the inventory data (see the next section). The containers considered can be visualised in Fig. 1, which also shows their packaging. 


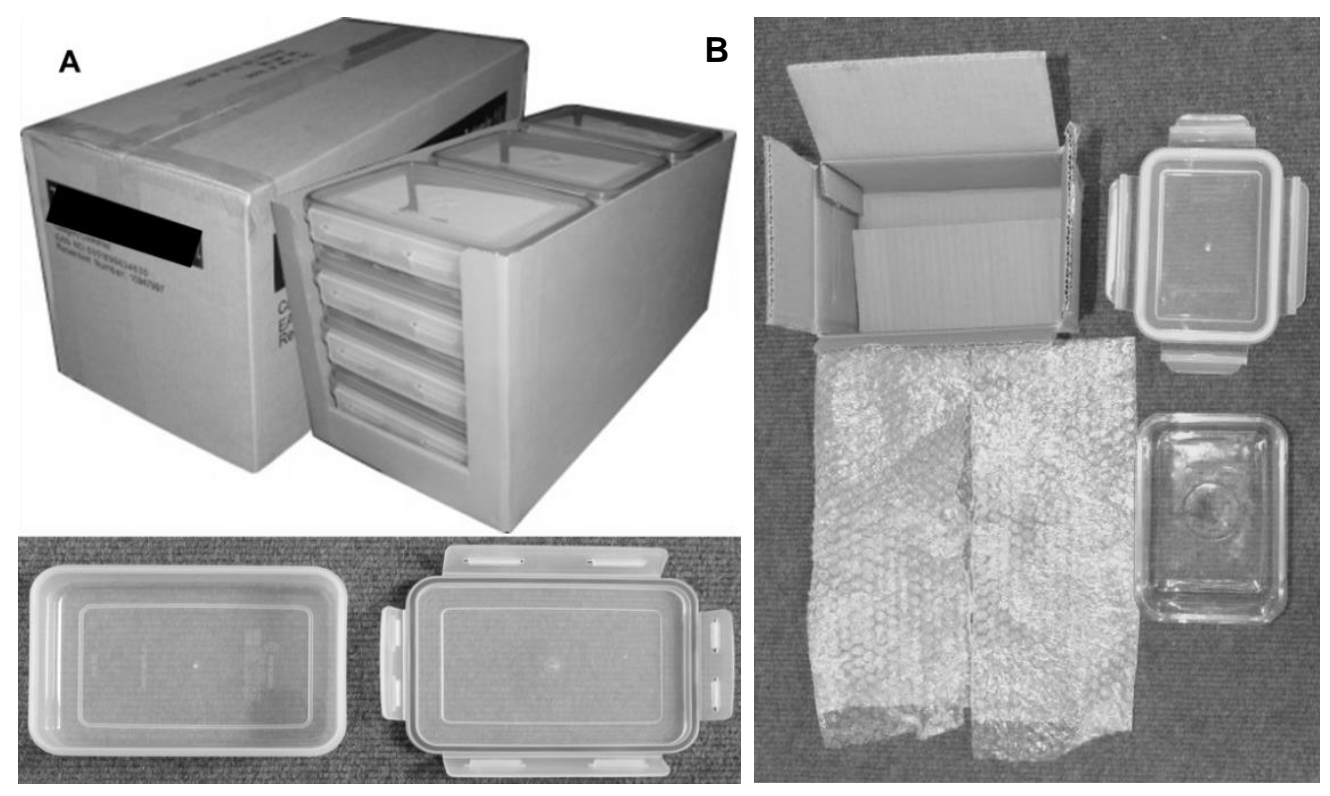

Fig. 1. Plastic (A) and glass (B) food savers with their packaging (cardboard boxes and bubble wrap).

The scope of the study is from 'cradle to grave' and the system boundaries include the following life cycle stages (Fig. 2):

- Extraction of raw materials and production of components:

o plastics: PP for the plastic food saver and the lid of both types of container; silicone for the lid seal; and polyethylene (PE) for the bubble wrap of the glass container

- glass: sodium carbonate (soda), lime, dolomite, silicon dioxide (silica), feldspar and recycled glass culets to make the glass for the body of the glass container

- cardboard for packaging of both types of food saver

- Production: extrusion and thermoforming of PP, silicone and PE; melting and tempering of glass; and production of packaging

- Use: manual and automatic washing of containers

- End-of-life waste management: disposal of waste generated throughout the life cycle and wastewater treatment

- Transport: distribution of raw materials, container components and packaging to the manufacturing facility, food savers to the retailer, production and post-consumer waste to treatment facilities.

The following is excluded from the system boundaries:

- energy consumption during storage at retailer;

- consumer transport to the retailer to buy the food saver;

- transport of food savers with food to the point of consumption (work) and back; and

- retail waste from any container breakage and its packaging.

\subsection{Inventory data}

The life cycle inventory ( $\mathrm{LCl}$ ) data for the plastic and glass food savers are detailed in Table 1. The bill of materials has been determined through own measurements and manufacturers' data. The background data have been sourced from Ecoinvent v3.1 (Moreno Ruiz et al., 2014) and any data gaps have been filled using the GaBi database (Thinkstep, 2016). 


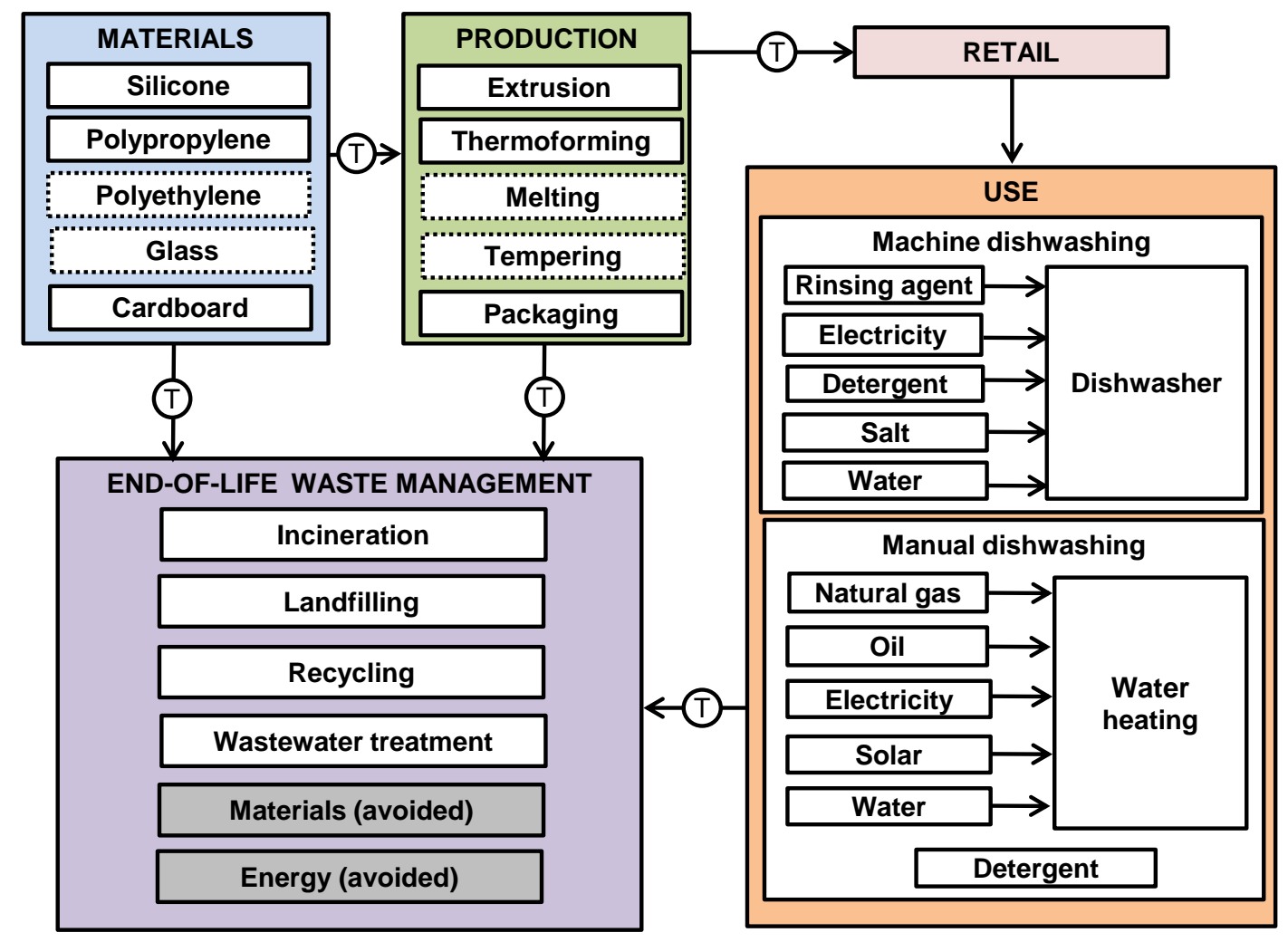

Fig. 2. System boundaries for the life cycle of plastic and glass food savers: solid boxes correspond to processes included in both systems and dashed boxes only to glass food savers. ( $T$ - transport.)

\subsubsection{Production of materials and food savers}

The materials used in the production of plastic food savers are PP and silicone. The container and the lid are made from PP, as this is the most commonly used plastic for microwavable food containers, because other plastics have poor resistance to high temperatures (Fellows and Axtell, 1993). Silicone is also used as part of the lid to facilitate the container closing and airtightness. Both raw materials are extruded and thermoformed to obtain the desired shape. The production of plastic food savers is mainly concentrated in South East Asia (Suwanmanee et al., 2013). Therefore, the Chinese electricity grid mix has been used to estimate the impacts of the production of these food savers. The primary production data have been obtained from a producer in China. After producing the lid and body, the food saver is manually assembled and packaged. Two cardboard boxes are used for packaging to transport 12 plastic food savers, as shown in Fig. 1.

The body of the glass container is made of tempered soda-lime glass, which is prepared by melting the raw materials (sodium carbonate (soda), lime, dolomite, silicon dioxide (silica), feldspar and recycled glass culets) in a furnace. The glass is then tempered, which is a special solidification process to make the glass more resistant to breakage. Also, in the event of breaking, the glass will not have any sharp edges, reducing the risk of injury. The amount of glass in the container has been obtained by own weighing. The food saver composition and description of the production processes have been obtained from manufacturers' websites and their customer service. The type and amount of materials used for the lid is the same as for the plastic food savers (Fig. 1) and, therefore, the same production processes have been considered. After the production of the lid and the body, the food saver is manually assembled and packaged. Due to the fragility of glass, more packaging is needed. Bubble wrap and a cardboard box are used for each food saver as primary packaging which is then placed in another carton box together with the other 23 containers. Due to the lack of specific data for this secondary packaging, the amount of cardboard used (39.6 $\mathrm{g}$ per food saver) has been calculated considering the volume 
occupied by 24 containers in their primary packaging. Also, due to the relatively high cost of transporting glass food savers, most are sold within a $500 \mathrm{~km}$ radius of the point of production (Scalet et al., 2013). Considering this, the European electricity mix has been considered for the production processes, taking 2014 as the base year due to the data availability.

Table 1. Inventory data for the plastic and the glass food savers

\begin{tabular}{|c|c|c|}
\hline & $\begin{array}{c}\text { Plastic } \\
\text { (polypropylene) }\end{array}$ & Glass \\
\hline \multicolumn{3}{|l|}{ Materials (g) } \\
\hline Polypropylene & 172 & 87 \\
\hline Glass & - & 575 \\
\hline Silicone & 10 & 10 \\
\hline \multicolumn{3}{|l|}{ Packaging (g) } \\
\hline Cardboard boxes & 29.9 & 57.4 \\
\hline Polyethylene & - & 12.2 \\
\hline \multicolumn{3}{|l|}{ Production (MJ) } \\
\hline Extrusion: electricity & 0.34 & 0.18 \\
\hline Extrusion: heat & 0.49 & 0.26 \\
\hline Thermoforming: electricity & 0.66 & 0.40 \\
\hline Thermoforming: heat & 0.07 & 0.05 \\
\hline Melting: electricity & - & 0.5 \\
\hline Melting: heat & - & 4.1 \\
\hline Tempering: heat & - & 0.77 \\
\hline Packaging: electricity & 0.01 & 0.02 \\
\hline Packaging: heat & 0.02 & 0.04 \\
\hline \multicolumn{3}{|l|}{ Transport $(\mathrm{tkm})^{a}$} \\
\hline Materials: by truck to factory $(150 \mathrm{~km})$ & 0.03 & 0.11 \\
\hline \multicolumn{3}{|l|}{ Food saver (PP body, PP lids and packaging): } \\
\hline By truck from factory to Shanghai port (150 km) & 0.03 & 0.02 \\
\hline $\begin{array}{l}\text { By container ship from Shanghai port to Rotterdam port }(19,500 \\
\text { km) }\end{array}$ & 4.12 & 3.25 \\
\hline $\begin{array}{l}\text { By truck from Rotterdam port to distribution centre in Munich (829 } \\
\mathrm{km} \text { ) }\end{array}$ & 0.18 & 0.14 \\
\hline $\begin{array}{l}\text { Food saver (glass body): by truck from factory to distribution centre in } \\
\text { Munich }(500 \mathrm{~km})\end{array}$ & - & 0.32 \\
\hline $\begin{array}{l}\text { Food savers (plastic and glass): by truck from distribution centre in } \\
\text { Munich to retailer }(150 \mathrm{~km})\end{array}$ & 0.03 & 0.11 \\
\hline $\begin{array}{l}\text { End-of-life waste: by truck to treatment facilities ( } 50 \mathrm{~km} \text { landfilling and } \\
100 \mathrm{~km} \text { incineration/recycling) }\end{array}$ & 0.17 & 0.62 \\
\hline \multicolumn{3}{|l|}{ Use: automatic washing } \\
\hline Electricity (MJ) & 4.7 & 4.7 \\
\hline Detergent $(\mathrm{g})$ & 18 & 18 \\
\hline Salt $(g)$ & 18 & 18 \\
\hline Rinsing agent $(g)$ & 3 & 3 \\
\hline Water $(\mathrm{L})$ & 13.7 & 13.7 \\
\hline \multicolumn{3}{|l|}{ Use: manual washing } \\
\hline Heat: natural gas (MJ) & 6.2 & 6.2 \\
\hline Heat: oil (MJ) & 0.9 & 0.9 \\
\hline Heat: electricity (MJ) & 2.6 & 2.6 \\
\hline Heat: solar (MJ) & 0.2 & 0.2 \\
\hline Water (L) & 113.3 & 113.3 \\
\hline Detergent $(\mathrm{g})$ & 38.5 & 38.5 \\
\hline \multicolumn{3}{|l|}{ End-of-life waste management $(g)$} \\
\hline Recycling: plastics & 18.7 & 9.4 \\
\hline Recycling: glass & - & 38.2 \\
\hline Recycling: cardboard & 24.8 & 61.5 \\
\hline Incineration with energy recovery: plastics & 75.6 & 390.7 \\
\hline Incineration with energy recovery: cardboard & 2.7 & 183.9 \\
\hline Landfilling: plastics & 87.7 & 48.3 \\
\hline Landfilling: glass & - & 5.2 \\
\hline Landfilling: cardboard & 2.1 & 4 \\
\hline
\end{tabular}


Ecoinvent data have been used for all the raw materials and production processes, except for the production of bubble wrap which were not available and have been sourced from Pilfold (2013) instead.

\subsubsection{Use of food savers}

The food savers must be washed after use, either by hand or in a dishwasher. Based on the number of dishwashers in the EU of 95.7 million (ECEEE, 2013) and 215.2 million households (Eurostat, 2017a), around $45 \%$ of European households regularly use a dishwasher. This is consistent with the estimates by others authors, such as Presutto et al. (2007). Therefore, it has been assumed that $45 \%$ of food savers are washed in a dishwasher and the rest by hand. As the volume of the plastic and glass food savers is the same $(1.1 \mathrm{~L})$, it has been assumed that the same cleaning requirements apply to both products. Inventory data for the consumption of water, detergent, salt and energy have been estimated (Table 1) based on the European studies developed by Stamminger et al. (2007) for hand dishwashing and Arendorf et al. (2014a) for dishwashers. Both studies considered 12 place standard settings (140 specific dishes and cutlery described in standard regulation EN 50242 (CENELEC, 2007)). These standard settings have been estimated here to be equivalent to 25 food savers in relation to the amount of resources needed for cleaning, considering the available volume of the dishwasher. The main components of the most commonly used detergents and rinsing agents have been obtained from Arendorf et al. (2014 a,b), Golsteijn et al. (2015) and Kaps et al. (2015). Average EU data on household water heaters have been considered (Kemna et al., 2007) to determine the energy sources used to heat water for manual washing up: electricity $(25.7 \%)$, natural gas $(62.9 \%)$, oil $(8.7 \%)$ and solar thermal energy (2.6\%). The impacts of manufacturing different types of boilers (Moreno Ruiz et al., 2014) and the dishwasher (Zhifeng et al., 2012) have also been considered. The type of dishwasher considered is a 12 place settings model that represents $86 \%$ of the EU market (IPTS, 2015). Finally, electricity profiles for Europe in Ecoinvent have been updated using the most recent data available (year 2014) (ENTSOE, 2016) and have been applied to model electricity consumption, both for manual and machine washing (see Table S1 in Supporting information (SI)).

\subsubsection{End-of-life waste management}

The waste generated in different life cycle stages is recycled, landfilled or incinerated with energy recovery (Fig. 2). The effluent from washing the food savers is treated in a wastewater treatment plant. For modelling the recyclable materials, the product systems have been credited by subtracting the equivalent impacts of virgin materials; however, the impacts from the recycling process are included. Following the 'net scrap' approach (Bergsma and Sevenster, 2013), the credits have only been given for the amount of recycled material that exceeds the recycled content in the original raw material. As detailed further below, due to the already high recycled content in the raw materials, the credits have only been applied to PP. The system has also been credited for the avoided electricity due to waste incineration with energy recovery.

The data for the disposal and wastewater treatment have been sourced from the Ecoinvent database, except for PP recycling for which specific data have been obtained from Schmidt (2012). PP and cardboard incineration with energy recovery have been modelled using $\mathrm{GaBi}$ data as these were not available in Ecoinvent. The EU electricity mix in 2014 (ENTSO-E, 2016) has been used to credit the system for the avoided impacts of electricity recovered from incinerating the plastic and cardboard.

The waste treatment rates and assumptions for different materials are as follows:

- Average data for the EU28 (excluding Croatia), Switzerland and Norway have been considered for PP waste management: 11\% recycling, 44\% incineration with energy recovery and $45 \%$ for landfilling (Lhôte, 2011). The PP used is $100 \%$ virgin and, therefore, the product system has been credited for the recycling of $11 \%$ of the PP. 
- For glass, $73 \%$ is recycled and $27 \%$ is landfilled at the European level (Eurostat, 2017b). A similar percentage of recycled glass is used for the food savers, so no environmental credit for the avoided material has been applied.

- For the cardboard packaging, packaging disposal data for the EU countries (excluding Croatia) have been assumed: $9 \%$ landfilling, $84 \%$ recycling and $7 \%$ incineration with energy recovery (Eurostat, 2017b). Due to the high recycled content in the raw materials, no environmental credit for the avoided material has been considered in this case.

- For silicone and polyethylene (bubble wrap), 100\% landfilling has been assumed.

- For the amount and treatment of waste generated during the production of raw materials, Ecoinvent data have been used due to a lack of specific data.

\subsubsection{Transport}

If not specified in the databases, the raw and packaging materials are assumed to travel a distance of $150 \mathrm{~km}$ from the processing plant to the food saver manufacturing facility in a 1632 t Euro 3 truck. After the final assembly and packaging in China, the plastic food savers are transported $150 \mathrm{~km}$ from the production site to the port in Shanghai (16-32 t Euro 3 truck) to be shipped to Europe. The maritime route $(19,500 \mathrm{~km})$ by transoceanic tanker between two principal commercial ports in China (Shanghai) and Europe (Rotterdam) has been considered (Sea Distance, 2018). The food savers are then transported by 16-32 $\mathrm{t}$ Euro 6 truck to a distribution centre in a central point of the EU (the city of Munich, $829 \mathrm{~km}$ ) (Via Michelin, 2018). From there, they are distributed to the retailer (16-32 t Euro 6 truck), assuming a distance of $150 \mathrm{~km}$.

For the glass food savers, the same distribution route as for the plastic container has been considered for the lid and the packaging, but the glass body and the container assembly are considered to be $500 \mathrm{~km}$ from the distribution centre in Munich, transported there in a 16-32 $\mathrm{t}$ Euro 6 truck. The transportation of end-of-life waste to disposal is assumed to be by a 16-32 t Euro 6 truck to a distance of $50 \mathrm{~km}$ for landfilling and $100 \mathrm{~km}$ for incineration and recycling.

\subsubsection{The EU level: current situation and future scenarios}

This section provides an overview of the assumptions for the estimation of the impacts from the food savers at the EU level for the current situation (2014) and future scenarios (2020). First, the method for estimating the number of food savers in use in the EU is presented, followed by the definition of improvement opportunities and scenarios considered.

\subsubsection{Food savers in use in the EU}

The number of employees eating home-made meals at work has been considered to determine the number of food savers in use. As mentioned in the introduction, $42 \%$ of 144.4 million employees in the EU bring home-made meals to eat at work. Thus, given the average number of working days of 227 per year (Eurofound, 2012), more than 13.767 billion homemade meals are taken to work annually. Therefore, for the 50 uses of each container (the functional unit), 275.34 million food savers are used in the EU per year.

To determine the market split between the PP and glass containers in the EU, a market research has been carried out as part of this work. Five countries have been considered for these purposes, representing 63\% of the EU population (Eurostat, 2017c): France, Germany, Italy, Spain and the UK. Out of the 40 bestselling food saver brands considered, it has been found that (Amazon France, 2016; Amazon Germany, 2016; Amazon Italy, 2016; Amazon Spain, 2016; Amazon UK, 2016):

- in France, 34 brands use PP and six glass;

- in Germany and Spain, this split is 35 and five in favour of PP;

- in Italy, only one out of 40 container types is made of glass; and

- in the UK, all 40 food saver brands use PP. 
Based on these results and extrapolating to the EU level, $90 \%$ of food savers are plastic and the rest are glass. Thus, out of the estimated 275.34 million food savers used annually in the EU, 247.8 million are plastic and 27.5 million are made of glass. The same number of food savers has been considered for the year 2020 due to a lack of specific market data. The plastic and glass food savers described in section 2.2 have been considered as a reference as the bestselling food savers in the above five countries have a similar design and volume.

\subsubsection{Improvement opportunities}

The improvement opportunities considered here focus on the use stage. As discussed in the introduction, this is due to the need to wash the containers which requires energy, water and detergents and could lead to significant impacts over the lifetime. The following three improvement options are evaluated for the future scenarios:

i) increasing the share of low-carbon electricity sources;

ii) implementing the eco-design regulation for dishwashers; and

iii) improving the efficiency of hand washing of containers.

i) Low-carbon electricity: It is expected that the share of low-carbon electricity in the EU mix will increase from the current $58.9 \%$ to $60.7 \%$ by 2020 (ENTSO-E, 2014); for details, see Table S1 in the SI. Although this represents a relatively small increase, it may still have a noticeable effect at the EU level on reducing the impacts associated with the washing of food savers.

ii) Eco-design of dishwashers: The EU regulation No 1016/2010 for the eco-design of household dishwashers (European Commission, 2010) identifies the BAT on the market as a benchmark. Its main objective is that all dishwashers sold in the EU should have at least the same efficiency as the BAT in the near future. The implementation of the BAT is mandatory for all new dishwashers sold from 2014 onwards. For the type of household dishwasher considered in this study (12 place settings), this implies a reduction in electricity consumption from 1.42 to $0.95 \mathrm{kWh}$ and water use from 15.2 to 9 L per cycle (European Commission, 2010; Arendorf et al., 2014a). These reductions have been considered for this improvement opportunity.

iii) Improved efficiency of hand dishwashing: The efficiency of manual cleaning of food savers to reduce resource consumption can be optimised by applying various techniques. For example, Fuss et al. (2011) developed washing up "tips" for consumers (see Table S2 in SI) that can save around $60 \%$ of water, $70 \%$ of energy and $30 \%$ of detergent while achieving the same level of cleanness as conventional manual dishwashing. The effect of applying these measures on the impacts of food savers has been assessed within this work.

\subsubsection{Description of scenarios and assumptions}

As indicated in Table 2, the following three scenarios are considered for the year 2020:

i) Pessimistic: In this scenario, only the reduced-carbon electricity mix is achieved based on the targets set in the EU's Renewable Energy Directive 2009/28/EC (European Parliament and Council, 2009).

ii) Conservative: Here, both the low-carbon electricity and eco-design options are realised. Regarding the latter, it is assumed that all dishwashers represent the BAT in 2020, in compliance with the eco-design regulation for household dishwashers (European Commission, 2010). This assumption depends on several factors, such as the type of dishwasher, lifetime, sales and units in stock in future years. Taking into consideration that the eco-design regulation for 12-place settings dishwashers entered into force in 2014 and with the available estimates of sales and units in stock (see Table S3 in SI), it can be established that the majority of the models in use (>82\%) will be compliant with the eco-design regulation by 2020 . The improved hand washing is not realised in this scenario because no specific EU regulation is planned to help improve consumer behaviour. 
iii) Optimistic: This scenario sees all three options fully implemented by 2020 . The implementation of the improved manual dishwashing can be considered an idealistic assumption which could be difficult to achieve in reality, as it depends on human behaviour. Nevertheless, $80 \%$ of the participants in the previously-mentioned study by Fuss et al. (2011) agreed that the suggested techniques for improving dishwashing were easy to apply (Table S2). In any case, the purpose of this scenario is to show the potential environmental savings at the EU level if this improvement option was achievable.

Table 2. Improvement opportunities considered for the 2020 scenarios for food savers in the EU in comparison with the current situation

\begin{tabular}{lcccc}
\hline & Current & Future scenarios (2020) & \\
& situation (2014) & Pessimistic & Conservative & Optimistic \\
\hline Low-carbon electricity & No & Yes & Yes & Yes \\
Eco-design of dishwashers & No & No & Yes & Yes \\
Optimised manual dishwashing & No & No & No & Yes \\
\hline
\end{tabular}

\subsubsection{Sensitivity analysis}

The lifespan of the food savers is one of the parameters with the highest uncertainty as it is highly dependent on user behaviour. Based on the average usage data reported by Accorsi et al. (2014), 50 uses have been assumed in the base case for both the plastic and glass food savers. However, Accorsi and co-workers also considered a maximum lifespan of 70 uses of plastic containers while Harnoto (2013) established their average reuse at 43. Therefore, these two lifespans are considered for the current situation as part of the sensitivity analysis at the EU level. Given that the glass containers may be more durable than the plastic, a further sensitivity analysis considers expanding the lifespan of glass containers to a full working year (227 uses) to examine the effect of this parameter on the relative difference in the impacts between the two types of food saver. Note that the change in the lifetime of the containers also means the change in the number of food savers in use at the EU level. For the same number of annual uses of 13.767 billion, the following number of containers is needed:

- 70 uses of plastic containers, while keeping 50 uses of glass containers as in the base case: 204.54 million (170 million plastic and 27.53 million glass containers);

- 43 uses of plastic containers with 50 uses of glass containers: 315.68 million (288.15 million plastic and 27.53 million glass containers); and

- 50 uses of plastic containers and 227 uses of glass containers: 254.15 million (247.81 million plastic and 6.34 million glass containers).

The above compares with the base case scenarios with the total number of containers of 275.34 million, of which 247.81 million are plastic and 27.53 million are glass food savers.

\subsection{Impact assessment}

GaBi 6.5. LCA software (Thinkstep, 2016) has been used to model the life cycle of the food savers. The latest available version of CML 2001 (January 2016 version) impact assessment method has been used to calculate the environmental impacts (Guinee et al., 2001). The following impacts are considered: primary energy demand (PED), abiotic depletion potential of elements $\left(A D P_{e}\right)$, abiotic depletion potential of fossil resources $\left(A D P_{f}\right)$, acidification potential (AP), eutrophication potential (EP), global warming potential (GWP), human toxicity potential (HTP), marine aquatic ecotoxicity potential (MAETP), freshwater aquatic ecotoxicity potential (FAETP), terrestrial ecotoxicity potential (TETP), ozone depletion potential (ODP) and photochemical oxidants creation potential (POCP). The results of the modelling are discussed in the next section. 


\section{Results and discussion}

First, the results are discussed for the reference plastic and glass food savers, followed by the estimation of their environmental impacts at the EU level.

\subsection{Comparison of plastic and glass food savers}

Fig. 3 compares the environmental impacts of plastic and glass food savers, also showing the contributions of different life cycle stages. Overall, the impacts associated with the glass food saver are between $12 \%\left(\mathrm{ADP}_{\mathrm{f}}\right)$ and $64 \%(\mathrm{ODP})$ higher than from the plastic container. For example, the plastic food saver will use $48 \mathrm{MJ}$ of primary energy and emit $2.3 \mathrm{~kg} \mathrm{CO}$ eq. over its service life. The equivalent values for the glass alternative are $54 \mathrm{MJ}$ and $2.7 \mathrm{~kg}$ $\mathrm{CO}_{2}$ eq., respectively. The main difference in the impacts between the food savers is due to their constituent materials because the use stage is the same for both and the contribution of transport and end-of life waste management is relatively small.

The use stage is the main hotspot for all impacts categories, contributing $48 \%-90 \%$ in the case of the plastic food saver and $41 \%-75 \%$ for the glass version. Machine dishwashing accounts for $22 \%-67 \%$ of the total impacts for the plastic and $17 \%-55 \%$ for the glass

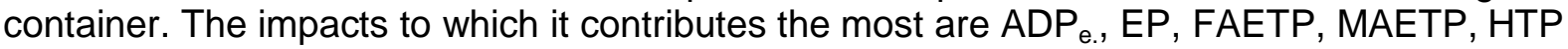
and TETP, all related to the use of electricity Hand washing contributes $>16 \%$ to all the impact categories from the plastic container and $>13 \%$ for the glass. The contribution of manual washing is particularly significant for PED, ADP f. AP, GWP, ODP and POCP. This is largely due to the use of natural gas to heat the water. Further details on the main hotspots, see Tables S4 and S5 in SI.

Production of materials plays a notable role in the case of plastic food savers for PED, $A D P_{f}$, GWP, POCP and ODP, contributing between 15\% and 35\% (Fig. 3). The last is due to the production of silicone and the other four impacts are related to the production of PP granulates. For the glass food saver, the materials are also the main cause of these five impacts, but to a somewhat lower extent (15\%-26\%). In addition, the contribution to ADP $_{\mathrm{e}}$ is significant $(20 \%)$, related to the consumption of sodium chloride used to produce soda, which is in turn used in the production of glass.

The manufacture of the containers is a less significant contributor for the plastic variety $(7 \%$ $14 \%$ ), with an exception of AP to which it contributes $18 \%$. The main causes of this impact are $\mathrm{SO}_{2}$ emissions associated with electricity consumption and, to a lesser extent, the heat used in the extrusion and thermoforming of plastics. The use of fossil fuels in these processes is the main contributor (10\%-14\%) to six other impacts: EP, GWP, HTP, MAETP, ODP and POCP. For the glass food saver, the production stage contributes more than $12 \%$ to all impact categories and exceeds $25 \%$ for AP, GWP, HTP, MAETP, ODP and POCP. These impacts are related to the emissions of $\mathrm{CO}_{2}, \mathrm{SO}_{\mathrm{x}}, \mathrm{HF}$ and selenium from fossil fuels used in the glass melting furnace and for the tempering process.

As mentioned earlier, the contribution to the impacts of transport and end-of-life waste management is relatively low $(<10 \%)$ for both types of food saver. The end-of-life stage has an overall positive effect on two impacts $\left(A D P_{f}\right.$ and $\left.P E D\right)$ for plastic containers and five impacts $\left(\mathrm{ADP}_{\mathrm{f}}, \mathrm{AP}, \mathrm{ODP}, \mathrm{POCP}\right.$ and PED) for glass containers because of the recycling credits. However, the credits are small: $<4 \%$ for the plastic and $<2 \%$ for the glass container. 


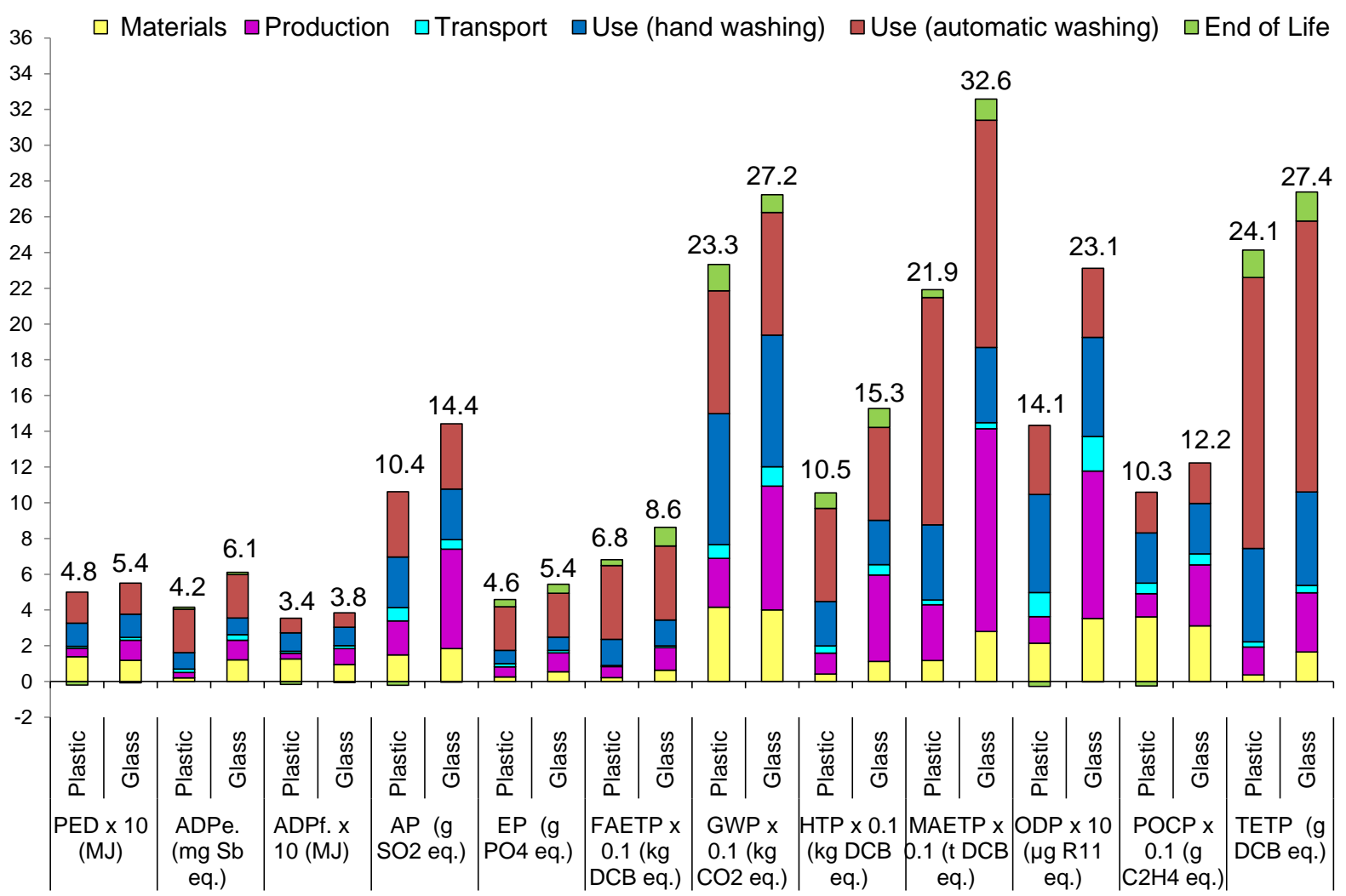

Fig. 3. Life cycle environmental impacts of plastic and glass food savers over 50 uses (The values shown on top of each bar represent the total impact after the system credits have been applied and should be multiplied by the factor shown in brackets for the relevant impacts to obtain the original values. Impacts: PED: primary energy demand, $\mathrm{ADP}_{\mathrm{e}}$ : abiotic depletion potential of elements, ADP $_{\mathrm{f} .}$ : abiotic depletion potential of fossil resources, AP: acidification potential, EP: eutrophication potential, GWP: global warming potential, HTP: human toxicity potential, MAETP: marine aquatic ecotoxicity potential, FAETP: freshwater aquatic ecotoxicity potential, ODP: ozone layer depletion potential, POCP: photochemical oxidants creation potential, TETP: terrestrial ecotoxicity potential. DCB: dichlorobenzene.)

\subsubsection{Lifespan of glass food savers}

As shown in the previous section, the glass food savers have higher impacts than the plastic for all the impact categories, assuming the same lifespan (50 uses) for both. However, the impacts of the glass container can be reduced by a longer lifetime, resulting in a greater number of uses. Therefore, this section sets out to find out how many times the glass container must be used to match the impacts of the plastic container. The number of uses is specific for each impact category as it depends on the difference between the containers for each impact. As the impact from their use is the same, it can be excluded from the estimations. Therefore, the number of uses needed for the glass container can be estimated by first determining the glass-to-plastic impact ratio for each category (see Table 3 ) and then multiplying it by the number of uses of the plastic container (50). The results in Table 3 indicate that the glass container would need to be used from 1.3 up to 3.5 times longer than the plastic option. For example, the latter corresponds to the $\mathrm{ADP}_{\mathrm{e}}$ and would require the glass container to be used 175 times to equal this impact of the plastic container used 50 times. 
Table 3. The number of uses of a glass food saver necessary to equal the impacts of the plastic food saver

\begin{tabular}{|c|c|c|c|c|}
\hline \multirow[t]{2}{*}{ Impact category $^{\mathrm{a}}$} & \multicolumn{4}{|c|}{ Impacts for 50 uses excluding the use stage } \\
\hline & Plastic food saver & Glass food saver & Impact ratio & $\begin{array}{l}\text { Number of } \\
\text { uses of } \\
\text { glass food } \\
\text { saver }\end{array}$ \\
\hline PED (MJ) & 17.7 & 24 & 1.4 & 68 \\
\hline $\mathrm{ADP}_{\mathrm{e} .}(\mathrm{mg} \mathrm{Sb}$ eq.) & 0.8 & 2.8 & 3.5 & 175 \\
\hline $\mathrm{ADP}_{\mathrm{f} .}(\mathrm{MJ})$ & 15.3 & 19.4 & 1.3 & 63 \\
\hline $\mathrm{AP}\left(\mathrm{g} \mathrm{SO} \mathrm{SO}_{2}\right.$ eq. $)$ & 3.9 & 7.9 & 2 & 101 \\
\hline $\mathrm{EP}(\mathrm{g} \mathrm{PO}$ eq. $)$ & 1.4 & 2.3 & 1.6 & 82 \\
\hline FAETP (kg DCB eq.) & 0.1 & 0.3 & 3 & 150 \\
\hline GWP (kg CO 2 eq.) & 0.9 & 1.3 & 1.4 & 72 \\
\hline HTP (kg DCB eq.) & 0.3 & 0.8 & 2.7 & 133 \\
\hline MAETP (t DCB eq.) & 0.5 & 1.6 & 3.2 & 160 \\
\hline ODP ( $\mu \mathrm{g} \mathrm{R} 11$ eq.) & 47.1 & 137 & 2.9 & 145 \\
\hline POCP (g C ${ }_{2} \mathrm{H}_{4}$ eq. $)$ & 0.5 & 0.7 & 1.4 & 70 \\
\hline TETP (g DCB eq.) & 3.8 & 7 & 1.8 & 92 \\
\hline
\end{tabular}

\subsection{Analysis at the EU level}

\subsubsection{Current situation and future scenarios}

The current annual impacts from 275.34 million plastic and glass food savers used in the EU are shown in Fig. 4. For example, the GWP is estimated at $653.1 \mathrm{kt} \mathrm{CO}_{2}$ eq./year. To put this into context, the GWP is similar to the annual greenhouse gas emissions of Bermuda (632.9 kt $\mathrm{CO}_{2}$ ) in 2012 (Joint Research Centre, 2014).

The comparison of the impacts for the current situation with the Pessimistic scenario indicates that the lower-carbon electricity would reduce most impacts by $1 \%-22 \%$ (Fig. 4). The GWP would be $4 \%$ lower, representing an annual saving of $23,000 \mathrm{t} \mathrm{CO}_{2}$ eq. This amounts to the avoidance of using 20,500 light-duty vehicles annually (Winkler et al., 2014). The most significant potential savings are found for the EP, FAETP and MAETP which would decrease by around $20 \%$. This is despite the small increase in the share of low-carbon technologies in the electricity mix: from 58.9\% in 2014 to $60.7 \%$ in 2020 (see Table S1 in SI). The only exceptions are the $\mathrm{ADP}_{\mathrm{e}}$ and ODP which would increase by $22 \%$ and $6 \%$, respectively, due to the greater respective contributions from solar PV and gas in the assumed future electricity mix. Furthermore, TETP would remain similar to today's levels.

The implementation in the Conservative scenario with both the low-carbon electricity mix and the eco-design regulation for dishwashers would reduce the impacts by $3 \%-34 \%$ relative to the current situation. This includes a $12 \%$ saving in the GWP, amounting to $75,300 \mathrm{t} \mathrm{CO}_{2}$ eq./yr or the impact generated annually by around 67,000 light-duty vehicles (Winkler et al., 2014). The exception to this is $A D P_{e}$. which would increase by $6 \%$ as the reduction in the consumption of electricity through the implementation of the eco-design regulation is not enough to offset the greater depletion of elements due to the increased share of solar PV in the electricity mix. Comparison of the impacts for the Pessimistic and Conservative scenarios (Fig. 4) reveals that the implementation of the eco-design regulation alone would reduce the impacts by $6 \%-20 \%$ relative to the current situation. Thus, the potential savings in the impacts associated with the regulation are greater than those related to the decarbonisation of the electricity mix for most impacts. By contrast, the reductions in EP, FAETP and MAETP are greater from the decarbonisation of electricity. These results demonstrate clearly the importance of the full implementation of the eco-design regulation as 
it will help to reduce significantly the impacts associated with a product used daily by many Europeans.

Finally, in the Optimistic scenario, the impacts would be lower by $12 \%-47 \%$, with ten out of 12 categories being reduced by over $30 \%$. The GWP would go down by $33 \%$, saving $216,400 \mathrm{t} \mathrm{CO}_{2}$ eq. annually. This is equivalent to the annual greenhouse gas emissions from 192,000 light duty vehicles (Winkler et al., 2014). The more efficient manual dishwashing (see Table S2 in SI) alone would reduce the impacts by $12 \%-27 \%$ (the difference between the Conservative and the Optimistic scenario). For seven categories (ADP f. $_{\text {. }}$ AP, GWP, HTP, ODP, POCP and PED), improved dishwashing would lead to greater reductions in the impacts than the reduction in the carbon intensity of the electricity mix or the implementation of the eco-design regulation. Therefore, these findings show the importance of encouraging consumers to adopt more efficient washing up approaches, particularly as the study by Fuss et al. (2011) showed that consumers thought they were easy to implement. However, there is little awareness of these techniques among consumers. One of the ways to raise the awareness would be for manufacturers to provide best-practice dishwashing guidance on the packaging. However, simply providing more information to the consumer is unlikely to be effective and further research would be needed to explore how this issue could be addressed more effectively.

\subsubsection{Sensitivity analysis: Lifetime expectancy}

This section explores the effect of the lifetime expectancy on the impacts of food savers at the EU level. For this purpose, the impacts in the base case (50 uses) are compared to the impacts assuming a longer (70 uses) and shorter (43) lifetime for the plastic containers and a much longer (227 uses) lifespan for the glass food saver.

The results in Fig. 5 suggest that these changes do not affect significantly the impacts at the EU level. Reducing the service life of plastic food savers to 43 uses would increase the impacts by $1 \%-7 \%$, with the greatest increase observed for PED, ADP f. $_{\text {. }} A P$, GWP and POCP (5\%-7\%). Prolonging the lifetime to 70 uses would cause a modest decrease in impacts: $10 \%-13 \%$ for ADP $_{\text {f. }}$, GWP and POCP and $<9 \%$ for the remaining categories. However, it should be noted that the greater durability of the food savers would increase the relative contribution of the use stage to the impacts. For example, if all the plastic food savers in the EU had a durability of one year (227 uses), the use stage would be responsible for $86 \%$ of the GWP, instead of $61 \%$ when 50 uses are considered. Therefore, the necessity of applying the improvements in the use stage discussed earlier becomes even greater if the average lifetime of plastic food savers is increased.

Finally, increasing the lifetime of the glass food saver to 227 uses has a negligible effect on the impacts at the EU level, with the reductions $<7 \%$ in all the categories. The reason for this is the low percentage of glass food savers in use compared with the plastic (10\% vs $90 \%)$. This means that, at the EU level, changes in the service life of plastic food savers are much more influential. Therefore, future studies should focus on determining typical lifetimes of different types of container as well as their market share at the EU level. 


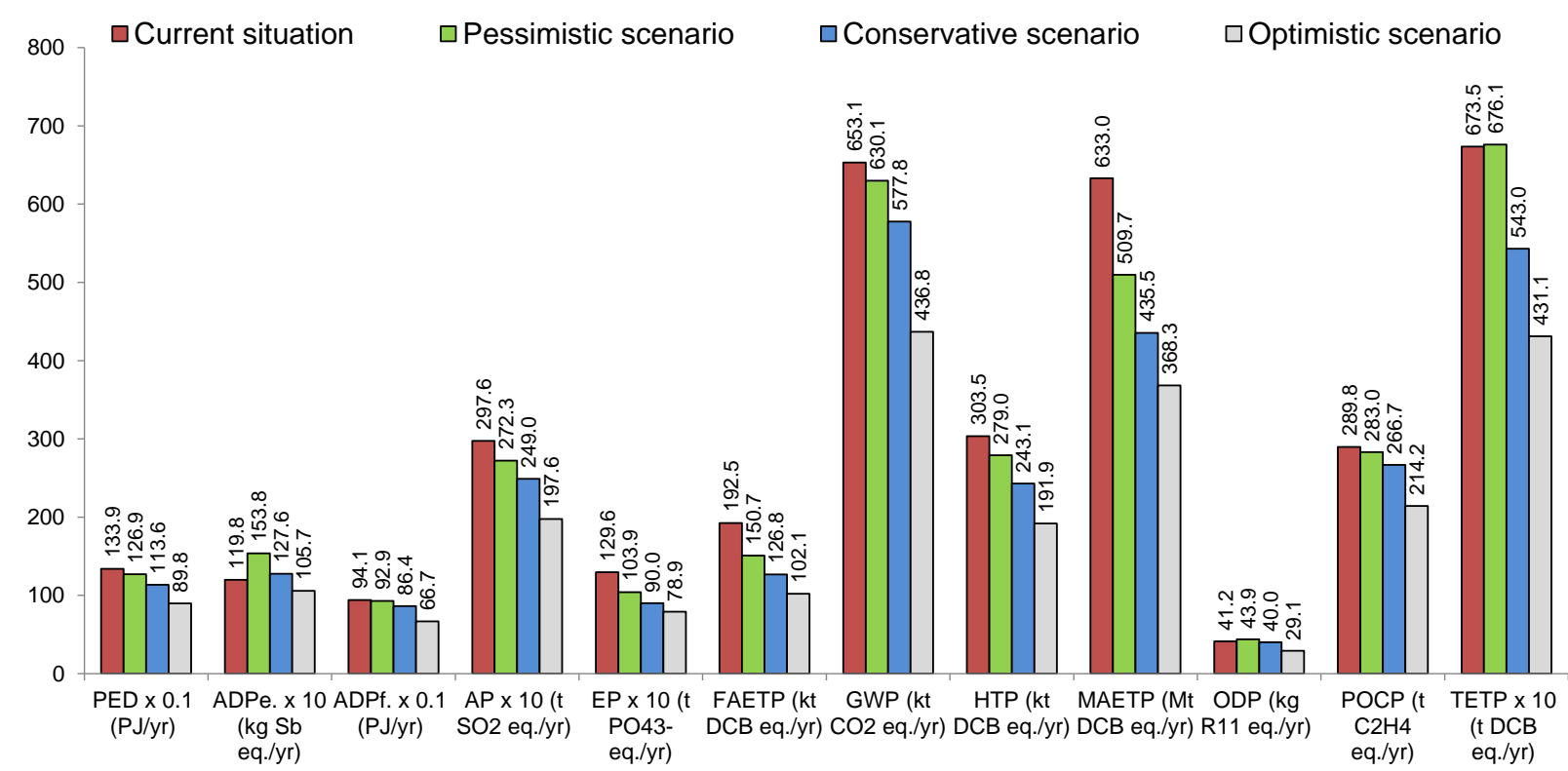

Fig. 4. Annual environmental impacts of food savers in the EU for the current situation (2014) and 2020 scenarios

(Basis: 275.34 million units. The values shown on top of each bar represent the total impact after the system credits have been applied and should be multiplied by the factor shown in brackets for the relevant impacts to obtain the original values. For the description of scenarios, see section 2.2.5. For the impacts nomenclature, see Fig. 3.)

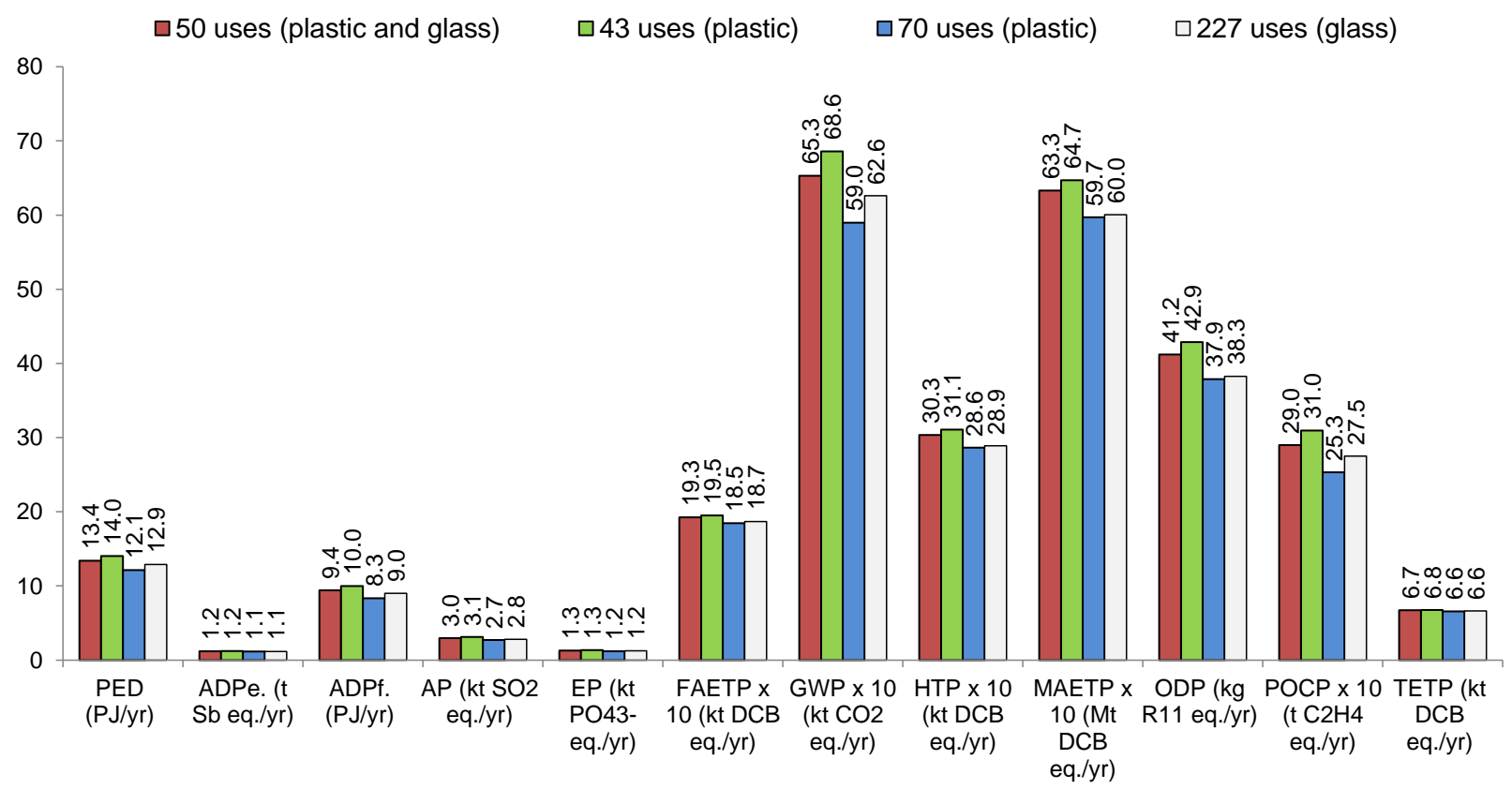

Fig. 5. Influence of the lifetime expectancy of the food savers on their annual environmental impacts at the EU level

(Basis: 13.767 billion uses. The values shown on top of each bar represent the total impact after the system credits have been applied and should be multiplied by the factor shown in brackets for the relevant impacts to obtain the original values. For the impacts nomenclature, see Fig. 3.) 


\section{Conclusions}

This study has provided the first comprehensive evaluation of the life cycle impacts of plastic and glass food savers and the implications of their use at the EU level. The results reveal that the glass container has $12 \%-64 \%$ higher impacts than the plastic and should have 1.33.5 times longer lifespan to equal the environmental footprint of the plastic containers, depending on the impact considered. The use stage is the main contributor $(>40 \%)$ to all environmental impacts for both types of food saver, mainly due to the use of electricity by the dishwasher and natural gas to heat water for hand washing up. Therefore, consumers can help to reduce the impacts of food savers by using efficient dishwashers or following recommendations for improved hand dishwashing. Consumers should aim to prolong the lifetime of food containers, particularly the glass, as they have higher environmental impacts than the plastic.

The production of container materials also plays an important role for both types of food saver, particularly for abiotic depletion of fossil elements, global warming, creation of photochemical oxidants and primary energy demand, contributing more than $15 \%$. The manufacture of the plastic food savers is a hotspot only for acidification but, for the glass food saver, this stage contributes significantly to global warming, human and maritime toxicity, ozone layer depletion and photochemical oxidants. Transport and end-of-life waste management have a small $(<10 \%)$ influence on the impacts.

The expected lower-carbon intensity of the European electricity mix in 2020 (Pessimistic scenario) would decrease the overall impacts by $1 \%-22 \%$ on the current values. The exceptions are the depletion of elements and ozone layer which would increase respectively due to the greater share of solar PV and natural gas in the electricity mix.

The combined effect of the lower-carbon electricity mix and the eco-design regulation for dishwashers (Conservative scenario) would decrease the impacts by $3 \%-34 \%$, apart from the depletion of elements which would increase by $6 \%$. The full implementation of the ecodesign regulation is crucial because it alone would reduce the impacts by $6 \%-20 \%$ compared with business as usual. It would also have a greater effect on reducing the impacts than the lower-carbon electricity for eight of the 12 impact categories considered. These results also show the significant indirect influence of some EU regulations (in this case eco-design of dishwashers and electricity decarbonisation) on environmental performance of products like food savers which are not subject to these or other related regulation.

Finally, in the best case (Optimistic scenario), the implementation of resource-efficient techniques for hand dishwashing together with the other two improvement options would reduce the impacts by $12 \%-47 \%$ compared to the current situation, with nine impacts decreasing by $>30 \%$. The contribution of the improved hand dishwashing to the total reductions would be $12 \%-27 \%$. Thus, this option has the greatest potential to improve the environmental sustainability of food savers and reduce the impacts from their use. These results demonstrate clearly the need for development of EU policies to help guide consumers towards reducing resource consumption related to hand dishwashing. An analysis of how to develop and implement these policies effectively should be a priority for future research. Given the environmental importance of cleaning the containers, future research should also study how non-reusable containers (e.g. aluminium or polystyrene trays used in the take-away food sector) compare to the reusable food savers.

\section{Acknowledgments}

This work was funded by the Sustainable Consumption Institute at the University of Manchester and the UK Engineering and Physical Sciences Research Council (EPSRC, Gr. no. EP/F007132/1). The authors gratefully acknowledge this funding. 


\section{References}

Accorsi, R., Cascini, A., Cholette, S., Manzini, R., Mora C., 2014. Economic and environmental assessment of reusable plastic containers: A food catering supply chain case study. Int. J. Prod. Econ. 152, 88-10.

Amazon France, 2016. Les meilleures ventes en ensembles de boîtes. Available at: http://www.amazon.fr/gp/bestsellers/kitchen/3305875031/ref=sr_bs_1\#1.

Amazon Germany 2016. Bestseller in Vorratsdosen. Available at: https://www.amazon.de/gp/bestsellers/kitchen/3437581031/ref=zg_bs_unv_k_5_331169_ 1.

Amazon Italy, 2016. Bestseller in Set di contenitori per alimenti. Available at: https://www.amazon.it/gp/bestsellers/kitchen/3473269031/ref=pd_zg_hrsr_kitchen_1_5_I ast.

Amazon Spain, 2016. Los más vendidos en taperes. Available at: https://www.amazon.es/gp/bestsellers/kitchen/2165236031/ref=pd_zg_hrsr_kitchen_1_5_ last.

Amazon UK, 2016. Best Sellers in Lunch Boxes. Available at: http://www.amazon.co.uk/Best-Sellers-Kitchen-Home-Lunch-Boxes/zgbs/kitchen/331354 7031.

Arendorf, J., Bojczuk, K., Sims, E., Menkveld, R., Golsteijn, L., Gaasbeek, A., Boyano, A., Medyna G., Kaps, R., 2014a. Preliminary report for the revision of European Ecological criteria for detergents for dishwashers: Domestic and industrial and institutional. Institute for Prospective Technical Studies (IPTS), Seville (Spain) $145 \mathrm{pp}$.

Arendorf J., Bojczuk, K., Skinner, D., Golsteijn, L., Gaasbeek, A., Boyano, A., Medyna, G. Kaps, R., 2014b. Preliminary report for the revision of ecological criteria for hand dishwashing detergents. Institute for Prospective Technical Studies (IPTS), Seville (Spain) 135 pp.

Bergsma, G., Sevenster, M. 2013. End-of-life best approach for allocating recycling benefits in LCAs of metal packaging. CE Delft, Delft (The Netherlands) $25 \mathrm{pp}$.

CENELEC, 2007. EN 50242/EN 60346. Electric dishwashers for household use - methods for measuring the performance. European Committee for Electrotechnical standardization, Brussels (Belgium) $28 \mathrm{pp}$.

DECC, 2015. Chapter 5: Electricity. Digest of UK Energy Statistics. Department of Energy and Climate Change, London $43 \mathrm{pp}$.

Duraccio, D., Silvestre, C., Pezzuto, M., Cimmino, S. Marra, A, 2013. Polypropylene and Polyethylene-Based Nanocomposites for Food Packaging Application. In: Ecosustainable Polymer Nanomaterials for Food Packaging: Innovative Solutions, Characterization Needs, Safety and Environmental Issues. Taylor and Francis Group, Boca Raton (USA) $392 \mathrm{pp}$.

Earth Talk, 2008. How safe is Tupperware? Can plastic food-storage containers leach hormone-disrupting chemicals into your leftovers? Available at: http://www.popsci.com/earthtalk/article/2008-08/how-safe-tupperware.

ECEEE, 2013. Estimating potential additional energy savings from upcoming revisions to existing regulations under the ecodesign and energy labelling directives: a contribution to the evidence base. European Council for an Energy Efficient Economy, Brussels (Belgium) $207 \mathrm{pp}$.

EFSA, 2015. Scientific Opinion on the risks to public health related to the presence of bisphenol A (BPA) in foodstuffs: Executive summary. European Food Safety Authority Journal 13(1), 3978.

ENTSO-E, 2011. Statistical Yearbook 2010. European Network of Transmission System Operators for Electricity, Brussels (Belgium) 68 pp.

ENTSO-E, 2014. Scenario Outlook and Adequacy Forecast (SO\&AF) 2014-2030 Dataset. European Network of Transmission System Operators for Electricity, Brussels (Belgium) $146 \mathrm{pp}$.

ENTSO-E, 2016. ENTSO-E Yearly Statistics \& Adequacy Retrospect 2014. European Network of Transmission System Operators for Electricity, Brussels (Belgium) 68 pp. 
Eurofound, 2012. Working time developments - 2011. European Foundation for the Improvement of Living and Working Conditions, Dublin (Ireland) 32 pp.

European Commission, 2010. Commission Regulation (EU) No 1016/2010 of 10 November 2010 implementing Directive 2009/125/EC of the European Parliament and of the Council with regard to ecodesign requirements for household dishwashers. Off. J. Eur. Union, L 293, 31-40 11.11.2010.

European Parliament and Council, 2009. Directive 2009/28/EC of the European Parliament and of the Council of 23 April 2009 on the promotion of the use of energy from renewable sources and amending and subsequently repealing Directives 2001/77/EC and 2003/30/EC. Off. J. Eur. Union, L 140, 16-62 5.6.2009.

Eurostat, 2017a. Number of private households by household composition, number of children and working status within households. Available at: http://appsso.eurostat.ec.europa.eu/nui/show.do?dataset=Ifst_hhnhwhtc\&lang=en

Eurostat, 2017b. Packaging waste statistics. Available at: http://appsso.eurostat.ec.europa.eu/nui/show.do?dataset=env_waspac\&lang=en.

Eurostat, 2017c. Population on 1 January. Available at: http://ec.europa.eu/eurostat/tgm/table.do?tab=table\&plugin=1\&language=en\&pcode=tps 0 0001.

Fellows P. and B. Axtell, 1993. Appropriate Food Packaging. Published by Transfer of Technology for Development-Amsterdam for International Labour Office - Geneva. Available at: http://collections.infocollections.org/ukedu/en/d/Jto01ae/.

FOOD Programme, 2015. Barometers from the European FOOD programme (Fighting Obesity through Offer and Demand). Available at: http://www.food-programme.eu/.

Fuss, N., Bornkessel, S., Mattern, T., Stamminger, R., 2011. Are resource savings in manual dishwashing possible? Int. J. Consum. Stud. 35, 194-200.

Fuss, N., Stamminger, R., 2010. Manual dishwashing: how can it be optimized? Int J Consum Stud 5, 342-348.

Girling, P.J., 2003. Packaging of food in glass containers. In: Coles R, McDowell D, Kirwan MJ, editors. Food packaging technology. Blackwell Publishing, Oxford, (U.K.) 152-173.

Golsteijn, L., Menkveld, R., King, H., Schneider, C., Schowanek D., Nissen, S., 2015. A compilation of life cycle studies for six household detergent product categories in Europe: the basis for product-specific A.I.S.E. Charter Advanced Sustainability Profiles. Environ. Sci. Eur. 27 (23), 1-12.

Guinee, J.B., Gorrèe, M., Heijungs, R., Huppes, G., Kleijn, G.R., van Oers, R.L., Wegener, L., Sleeswijk, A., Suh, S., de Haes, H.A. Udo, de Bruijn, H., van Duin, H.R., Huijbregts, M.A.J., 2001. Life Cycle Assessment, an Operational Guide to the ISO Standards. Part 2a: Guide. Kluwer Academic Publishers, Dordrecht (the Netherlands) 101 pp.

Harnoto, M., 2013. A comparative Life Cycle Assessment of compostable and reusable takeout clamshells at the University of California, Berkeley. Master Thesis, Berkeley (USA) 26 pp.

Harvard Health, 2015. Microwaving food in plastic: Dangerous or not? Available at: http://www.health.harvard.edu/staying-healthy/microwaving-food-in-plastic-dangerous-ornot.

IPTS, 2015. Ecodesign and Energy label revision: Household Dishwasher. Institute for Prospective Technical Studies, Seville (Spain) $164 \mathrm{pp}$.

ISO, 2006a. ISO14040:2006. Environmental management -- Life cycle assessment -Principles and framework. ISO standards, Geneva (Switzerland) $20 \mathrm{pp}$.

ISO, 2006b. ISO14044:2006 Environmental management - Life cycle assessment Requirements and guidelines. ISO standards, Geneva (Switzerland) $46 \mathrm{pp}$.

Joint Research Centre, 2014. Emission Database for Global Atmospheric Research (EDGAR), version 4.2. Available at: http://edgar.jrc.ec.europa.eu/overview.php?v=CO2ts1990-2011\&sort=des9.

Kaps, R., Medyna, G., Boyano, A., Parker, D., Chapman, A., 2015. Revision of European Ecolabel Criteria for the six detergent product groups. Institute for Prospective Technical Studies (IPTS), Seville (Spain) 263 pp. 
Kemna, E., van Elburg, M., Li, W., van Holsteijn, R., 2007. Preparatory study on Eco-design of water heaters. Task 3 Report (Final). Consumer behaviour and local infrastructure. Van Holsteijn en Kemna BV, Delft (The Netherlands) 87 pp.

Kuo, N.W., Hsiao, T.Y., Lan, C.F. 2005. Tourism management and industrial ecology: A case study of food service in Taiwan. Tourism Manage. 26 (4), 503-508.

Lhôte, S., 2011. The recycling and recovery of Polyolefins waste in Europe. Contribution to Identiplast 2011 Congress, Madrid (Spain), 03 ${ }^{\text {rd }}$ October 2011.

Madival, S., Auras, R., Singh S.P., Narayan, R., 2009. Assessment of the environmental profile of PLA, PET and PS clamshell container using LCA methodology. J. Clean. Prod. 17 (13), 1183-1194.

Marsh, K., Bugusu, B. 2007. Food Packaging—Roles, Materials, and Environmental Issues. J. Food Sci. 72 (3), 39-55.

Moreno Ruiz, E., Lévová, T., Bourgault, G., Wernet, G., 2014. Documentation of changes implemented in ecoinvent Data 3.1. Ecoinvet, Zurich (Switzerland) 70 pp.

NRDC, 2011. Food Storage Containers. Natural Resources Defense Council. Available at: http://www.nrdc.org/living/shoppingwise/food-storage-containers.asp.

Pilfold, K., 2013. A comparative life cycle assessment of protective mailers in the postal industry. PhD Thesis, Calgary (Canada) 124 pp.

Presutto, M., Schialdoni, R., Cutaia, L., Mebane, W., 2007. Preparatory Studies for Ecodesign Requirements of EUPs. LOT14: Domestic Washing Machines and Dishwashers. Task 5. ENEA, Ispra (Italy) 120 pp.

Razza, F., Fieschi, M., Innocenti, F. D., Bastioli, C., 2009. Compostable cutlery and waste management: An LCA approach. Waste Manage. 29 (4), 1424-1433.

Scalet, B. M., Garcia Muñoz, M., Sissa, A.V., Roudier, S., Delgado Sancho, L., 2013. Integrated Pollution and control (IPPC)-Reference document on Best Available Techniques in the Glass Manufacturing Industry. Institute for Prospective Technological Studies, Seville (Spain) 485 pp.

Schmidt, J.H., 2012. Plastberegner.dk-LCA tool for plastics converters in Denmark. Documentation of the tool and database. 2.-0 LCA consultants, Aalborg (Denmark) 126 pp.

Sea distance, 2018. Distance from Shanghai port to Rotterdam port. Available at: http://www.sea-distances.org/.

Stamminger, R., Elschenbroich, A, Rummler, B., Broil, G., 2007. Washing-up behaviour and techniques in Europe. HuW. 55 (1), 31-37.

Suwanmanee, U., Varabuntoonvit, V., Chaiwutthinan, P., Tajan, M., Mungcharoen, T., Leejarkpai, T., 2013. Life cycle assessment of single use thermoform boxes made from polystyrene (PS), polylactic acid, (PLA), and PLA/starch: Cradle to consumer gate. Int. J. Life Cycle Assess. 18 (2), 401-417.

Teichgraber, M., 2015. European Union Labour force survey - Annual results 2014. Available at: http://ec.europa.eu/eurostat/statisticsexplained/index.php/Labour_market_and_Labour_fo rce_survey_(LFS)_statistics

Thinkstep, 2016. Gabi 6.5 database. Thinkstep, Leinfelden-Echterdingen (Germany).

Tupperware, 2014. 2013 Fact sheet. Available at: http://s2.q4cdn.com/040648406/files/doc_factsheet/2013_Fact_Sheet.pdf.

Via Michelin, 2018. Distance from Rotterdam port to Munich. Available at: http://www.viamichelin.es/.

Winkler, S.L., Wallington, T.J., Maas, H., Hass, H., 2014. Light-duty vehicle $\mathrm{CO}_{2}$ targets consistent with 450 ppm CO 2 stabilization. Environ. Sci. Technol., 48 (11), 6453-6460.

Zhifeng, L., Yang, G., Di, H., Bo, L. 2012. Dishwasher's environmental impact analysis and improvement by addressing EUP directive in China dishwasher manufactures. Int. J. Environ. Techn. Manage. 15 (1), 61-78. 


\section{Supporting information}

Table S1 Electricity mix in the European Union countries (EU28) in 2014 and 2020

\begin{tabular}{lcc}
\hline Source of electricity & EU28 2014 $^{\text {a }}$ & EU28 $\mathbf{2 0 2 0}^{\mathbf{b}}$ \\
\hline Nuclear & $30.1 \%$ & $11.8 \%$ \\
Lignite & $10.8 \%$ & $5.7 \%$ \\
Hard coal & $15.7 \%$ & $10.8 \%$ \\
Natural gas & $13.3 \%$ & $20.7 \%$ \\
Oil & $1.3 \%$ & $2.2 \%$ \\
Wind & $8.5 \%$ & $18.6 \%$ \\
Solar & $3.2 \%$ & $11.0 \%$ \\
Biomass & $3.6 \%$ & $3.6 \%$ \\
Hydropower $^{c}$ & $13.5 \%$ & $15.7 \%$ \\
\hline
\end{tabular}

a Measured (ENTSO-E, 2016).

${ }^{\mathrm{b}}$ Based on net generation capacity (ENTSO-E, 2014).

${ }^{\mathrm{c}}$ Includes pumped storage.

Table S2. Techniques to optimise hand washing up (Fuss et al. 2011)

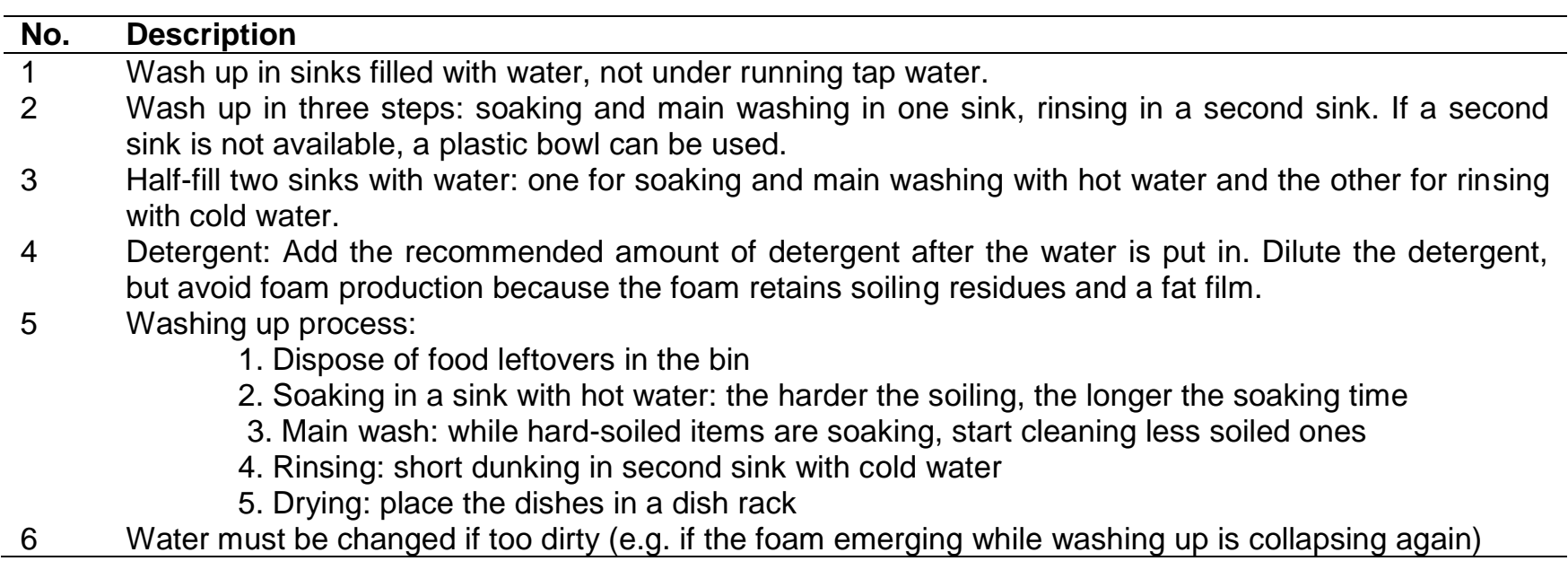

Table S3. Stock and sales of dishwashers for the period $2010-2025^{a}$

\begin{tabular}{rrr}
\hline Year & Stock (million units) & Sales (million units) \\
\hline 2010 & 82.2 & 7.4 \\
2011 & 85.6 & 7.7 \\
2012 & 89.0 & 8.0 \\
2013 & 92.3 & 8.2 \\
2014 & 95.7 & 8.5 \\
2015 & 99.1 & 8.8 \\
2016 & 102.1 & 9.0 \\
2017 & 106.7 & 9.2 \\
2018 & 110.6 & 9.4 \\
2019 & 114.4 & 9.6 \\
2020 & 118.2 & 9.8 \\
2021 & 122.0 & 10.0 \\
2022 & 125.7 & 10.2 \\
2023 & 129.7 & 10.5 \\
a Data from ECEEE $(2013)$ for years 2010, 2015, 2020 and 2025. The data for the remaining years have been estimated using linear \\
extrapolation.
\end{tabular}


Science of the Total Environment (2018), https://doi.org/10.1016/j.scitotenv.2018.02.128

Table S4. Hotspots in the life cycle of a plastic food saver

\begin{tabular}{|c|c|c|c|c|}
\hline Life cycle stage & Impact $^{a}$ & $\begin{array}{c}\text { Contribution } \\
\text { to the total } \\
(\%)\end{array}$ & Main contributor & $\begin{array}{c}\text { Contribution } \\
\text { to life cycle } \\
\text { stage (\%) }\end{array}$ \\
\hline \multicolumn{5}{|c|}{ Materials: polypropylene (PP) } \\
\hline & PED & 27.6 & Crude oil consumption & 62.7 \\
\hline & $\mathrm{ADP}_{\mathrm{f} .}$ & 35.2 & Crude oil & 62.7 \\
\hline & GWP & 18.0 & $\mathrm{CO}_{2}$ (PP production) & 84.3 \\
\hline & POCP & 34.0 & $\mathrm{NMVOC}^{\mathrm{b}}$ (PP production) & 71.6 \\
\hline \multicolumn{5}{|l|}{ Materials: silicone } \\
\hline \multirow{2}{*}{\multicolumn{5}{|c|}{ Use: hand washing (natural gas for heating water) }} \\
\hline & & & & \\
\hline & PED & 13.7 & Natural gas consumption & 96.5 \\
\hline & $\mathrm{ADP}_{\mathrm{f} .}$ & 18.9 & Natural gas & 98.0 \\
\hline & AP & 15.4 & $\mathrm{SO}_{2}$ (natural gas combustion) & 63.9 \\
\hline & GWP & 20.1 & $\mathrm{CO}_{2}$ (natural gas combustion) & 89.3 \\
\hline & ODP & 18.7 & Halon 1211 (natural gas transport) & 96.3 \\
\hline & POCP & 15.9 & NMVOC $^{\mathrm{b}}$ (natural gas combustion) & 25.5 \\
\hline \multicolumn{5}{|c|}{ Use: dishwasher (electricity for heating water) } \\
\hline & PED & 32.6 & U (nuclear energy) & 33.4 \\
\hline & $\mathrm{ADP}_{\mathrm{e}}$ & 40.4 & $\mathrm{Cu}$ (electricity distribution) & 48.7 \\
\hline & $\mathrm{ADP}_{\mathrm{f} .}$ & 21.0 & Fossil fuels consumption & 96.7 \\
\hline & AP & 30.9 & $\mathrm{SO}_{2}$ (coal combustion) & 81.6 \\
\hline & EP & 49.9 & $\mathrm{PO}_{4}^{3-}$ (coal mining) & 71.7 \\
\hline & FAETP & 57.6 & $\mathrm{Ni}$ (coal mining) & 41.8 \\
\hline & GWP & 27.6 & $\mathrm{CO}_{2}$ (fossil fuel combustion) & 82.0 \\
\hline & HTP & 45.1 & Se (coal mining) & 20.1 \\
\hline & MAETP & 54.2 & Be (coal mining) & 34.9 \\
\hline & ODP & 22.9 & Halon 1211 (natural gas transport) & 55.9 \\
\hline & POCP & 18.2 & $\mathrm{SO}_{2}$ (coal combustion) & 46.4 \\
\hline & TETP & 60.8 & Cr (electricity distribution) & 83.0 \\
\hline
\end{tabular}

${ }^{a}$ PED: primary energy demand, $\mathrm{ADP}_{\mathrm{e}}$ : abiotic depletion potential of elements, $\mathrm{ADP}_{\mathrm{f} .}$ : abiotic depletion potential of fossil resources, AP: acidification potential, EP: eutrophication potential, GWP: global warming potential, HTP: human toxicity potential, MAETP: marine aquatic ecotoxicity potential, FAETP: freshwater aquatic ecotoxicity potential, ODP: ozone layer depletion potential, POCP: photochemical oxidants creation potential, TETP: terrestrial ecotoxicity potential.

${ }^{b}$ NMVOC: Non-methane volatile organic compounds. 
Table S5. Hotspots in the life cycle of a glass food saver

\begin{tabular}{|c|c|c|c|c|}
\hline Life cycle stage & Impact $^{\mathrm{a}}$ & $\begin{array}{c}\text { Contribution to } \\
\text { the total (\%) }\end{array}$ & $\begin{array}{l}\text { Main } \\
\text { contributor }\end{array}$ & $\begin{array}{c}\text { Contribution } \\
(\%)\end{array}$ \\
\hline \multicolumn{5}{|l|}{ Materials: glass } \\
\hline \multirow{2}{*}{\multicolumn{5}{|c|}{$\begin{array}{c}\mathrm{ADP}_{\mathrm{e}} \\
\text { Materials: polypropylene (PP) }\end{array}$}} \\
\hline & & & & \\
\hline & PED & 16.1 & Crude oil & 62.7 \\
\hline & $\mathrm{ADP}_{\mathrm{f}}$ & 20.0 & Crude oil & 62.7 \\
\hline & GWP & 11.7 & $\mathrm{CO}_{2}$ (PP production) & 84.3 \\
\hline & POCP & 18.9 & NMVOC $^{\mathrm{b}}$ (PP production) & 71.6 \\
\hline \multicolumn{5}{|c|}{ Materials: silicone } \\
\hline & ODP & 8.3 & R12 (Dichlorodifluoromethane) & 91.2 \\
\hline \multicolumn{5}{|c|}{ Production: melting } \\
\hline & PED & 14.7 & Fossil fuels consumption & 86.9 \\
\hline & $\mathrm{ADP}_{\mathrm{e}}$ & 14.9 & $\mathrm{Cu}$ (electricity distribution) & 31.1 \\
\hline & $\mathrm{ADP}_{\mathrm{f} .}$ & 17.3 & Fossil fuels consumption & 100.0 \\
\hline & AP & 31.0 & $\mathrm{SO}_{2}$ (natural gas combustion) & 79.5 \\
\hline & EP & 13.7 & $\mathrm{NO}_{\mathrm{x}}$ (natural gas combustion) & 42.8 \\
\hline & FAETP & 10.4 & $\mathrm{Be}$ (waste treatment) & 37.7 \\
\hline & GWP & 18.6 & $\mathrm{CO}_{2}$ (fossil fuel combustion) & 95.8 \\
\hline & HTP & 27.1 & Se (natural gas combustion) & 64.1 \\
\hline & MAETP & 29.4 & HF (natural gas) & 53.4 \\
\hline & ODP & 30.6 & Halon 1211 (natural gas transport) & 38.1 \\
\hline & POCP & 21.3 & $\mathrm{SO}_{2}$ (natural gas combustion) & 58.1 \\
\hline & TETP & 8.6 & $\mathrm{Cr}$ (wastewater treatment) & 36.6 \\
\hline \multicolumn{5}{|c|}{ Use: hand washing (natural gas for heating water) } \\
\hline & PED & 12.6 & Natural gas consumption & 96.5 \\
\hline & $\mathrm{ADP}_{\mathrm{f}}$ & 17.8 & Natural gas & 98.0 \\
\hline & $A P$ & 11.5 & $\mathrm{SO}_{2}$ (natural gas combustion) & 63.9 \\
\hline & GWP & 17.1 & $\mathrm{CO}_{2}$ (natural gas combustion) & 89.3 \\
\hline & ODP & 11.7 & Halon 1211 (natural gas transport) & 96.3 \\
\hline & POCP & 13.9 & NMVOC $^{b}$ (natural gas combustion) & 25.5 \\
\hline \multicolumn{5}{|c|}{ Use: dishwasher (electricity for heating water) } \\
\hline & PED & 16.1 & U (nuclear energy) & 33.4 \\
\hline & $\mathrm{ADP}_{\mathrm{e}}$ & 27.1 & $\mathrm{Cu}$ (electricity distribution) & 48.7 \\
\hline & $\mathrm{ADP}_{\mathrm{f}}$ & 19.0 & Fossil fuels consumption & 96.7 \\
\hline & AP & 22.5 & $\mathrm{SO}_{2}$ (coal combustion) & 81.6 \\
\hline & EP & 42.0 & $\mathrm{PO}_{4}^{3-}$ (coal mining) & 71.7 \\
\hline & FAETP & 44.1 & $\mathrm{Ni}$ (coal mining) & 41.8 \\
\hline & GWP & 22.6 & $\mathrm{CO}_{2}$ (fossil fuel combustion) & 82.0 \\
\hline & HTP & 29.4 & Se (coal mining) & 20.1 \\
\hline & MAETP & 35.9 & Be (coal mining) & 34.9 \\
\hline & ODP & 13.4 & Halon 1211 (natural gas transport) & 55.9 \\
\hline & POCP & 15.4 & $\mathrm{SO}_{2}$ (coal combustion) & 46.4 \\
\hline & TETP & 18.9 & $\mathrm{Cr}$ (electricity distribution) & 83.0 \\
\hline
\end{tabular}

${ }^{a}$ For impacts nomenclature, see Table S4.

${ }^{b}$ NMVOC: Non-methane volatile organic compounds.

\section{References}

ECEEE (2013). Estimating potential additional energy savings from upcoming revisions to existing regulations under the ecodesign and energy labelling directives: a contribution to the evidence base. European Council for an Energy Efficient Economy, Brussels (Belgium).

ENTSO-E (2016) ENTSO-E Yearly Statistics \& Adequacy Retrospect 2014. European Network of Transmission System Operators for Electricity, Brussels (Belgium).

ENTSO-E (2014). Scenario Outlook and Adequacy Forecast (SO\&AF) 2014-2030 Dataset. European Network of Transmission System Operators for Electricity, Brussels (Belgium).

Fuss, N., S. Bornkessel. T. Mattern and R. Stamminger (2011). Are resource savings in manual dishwashing possible? Int J Consum Stud 35, pp. 194-200. 